\title{
Determinants of workers health and safety in the Malaysian wooden furniture industry
}

\begin{abstract}
Despite its socioeconomic importance and the labour intensive nature of the sector, the status of the health and safety of the workers in the Malaysian wooden furniture industry has not been studied and reports on the subject is sparse. Therefore, the safety climate, which defines the safety level of the work environment, in the Malaysian wooden furniture industry was studied in thirty wood-furniture manufacturing factories, using a structured questionnaire. The study found that although there were four determinants of the prevailing safety climate in the work environment, it was the management responsibility and safety precautions that had the strongest influence on safety climate. Further, the primary health and safety concerns in the wooden furniture manufacturing industry were the air-borne dust, noise, chemical exposure, materials handling and occupational accidents. In this context, it is essential for the management to show commitment towards health and safety and incorporate safety precautions into the operational system, to ensure a safe working environment in the wooden furniture manufacturing industry.
\end{abstract}

Keyword: Safe work environment; Safety climate; Safety practices; Safety precautions; Wooden furniture industry 